\title{
6. The art and science of influence: reflections from the boundary
}

\author{
Sharon Goldfeld
}

In Malcom Gladwell's book The Tipping Point: How little things can make a big difference (2002), he outlines how focusing on a number of key principles can assist in using evidence-based ideas (for example, the effects of climate change) to create social change. These three principles are centred on: 1) the law of the few - social change is often heavily dependent on a few people who are leaders, assisted by others who connect with and transmit the message; 2) the 'stickiness factors' - special characteristics of a message that render it so memorable that the message 'sticks'; and 3) the power of context - the idea that people are more sensitive to the influence of their environment or context (as opposed to individual character traits) than has previously been thought. Gladwell emphasises that social change requires an iterative process, with attention to detail around all three of the core principles. Through these three principles, Gladwell has, perhaps unwittingly, outlined what could be thought of as the core processes that help underpin the role of the knowledge broker as a key agent of change.

Gladwell's approach offers a useful framework for reflecting on the processes that might be necessary for effective knowledge brokering to capitalise on the research/policy nexus. In transferring this approach into the policy context, there is therefore the need for: 1) developing the evidence-based memorable message; 2) an understanding of the political context (the power of context); and 3) the ability to influence leadership. While many authors have analysed and considered the limited science of knowledge brokering, it could be that in order to effect real change the art of influence must be given equal attention.

In order to build on Gladwell's thinking, the starting point for this chapter has to be a better understanding of what knowledge brokering might mean in the current political and policy context in Australia and internationally. This requires not only an explanation and discussion of the definitions of knowledge brokering, but also a reflection on the skills that might be necessary for knowledge brokers in order to influence social change - particularly for children - in the current policy and political environment. This chapter will focus on examples of knowledge-brokering processes that have attempted to influence outcomes for children and families. It is written from the perspective 
Bridging the 'Know-Do' Gap

of someone in the somewhat unusual position of having a 'foot in two camps': a part-time postdoctoral research and clinical position and a policy position in a government department.

\section{What is a knowledge broker?}

There are now a number of terms being used to describe the general process of bringing together the research and policy worlds. While the terminology is relatively recent, the idea of researchers actively influencing policy has a long tradition, reaching well back into the annals of public health research. In the past, research has at times had a profound influence on policy and the subsequent funding of infrastructure, thereby improving the lives of hundreds of thousands of children-for example, John Snow's research into cholera transmission and the subsequent closure of the Broad Street water pump (Snow 1885). Today, in the developed world, the change processes appear to be more complex and incremental, the 'research ammunition' for influence less dramatic and the policy levers for change disconnected from where the final benefits emerge (for example, quality preschooling associated with decreased crime) (National Research Council Institute of Medicine 2000). Nevertheless, there are still substantial opportunities for research to benefit the present and future lives of children.

The following definitions from the Canadian Health Services Research Foundation (CHSRF) have merged from the relatively recent (historically speaking) surge in interest in evidence-based practice and policymaking (Bronson et al. 2006) and the need to make more explicit an understanding of the processes and roles considered necessary for success.

The CHSRF has an international reputation as a leader in knowledge transfermore recently renamed 'knowledge exchange'. It describes knowledge exchange as the interaction between decision makers and researchers that results in mutual learning through the process of planning, producing, disseminating, and applying existing or new research in decision-making'. The CHSRF separates knowledge exchange from knowledge brokering, which it describes as 'supporting evidence-based decision-making in the organization, management, and delivery of health services'. Knowledge brokering is, then, the active process that links researchers and decision makers (or practitioners) so that they are better able to 'understand each other's goals and professional culture, influence each other's work, forge new partnerships, and use research-based evidence' (Canadian Health Services Research Foundation 2008). Knowledge brokering seems necessary for knowledge exchange. The key link for these processes is the knowledge broker: the individual or organisation that facilitates action. 
A difficulty with these definitions is that their apparent simplicity belies the complexity of the process in real terms. These definitions also-perhaps for the sake of brevity-ignore the importance of the need for change as a key process driver. It can be argued that knowledge transfer or exchange processes facilitate change best when there is a clear goal in sight, with a strategy that articulates how the knowledge broker can use these processes to act as an agent of social change. The role of the knowledge broker is therefore shifted from a potentially passive or facilitative role to that of a driver of change, requiring a number of skills including the capacity to communicate across professional paradigms, to understand different contexts and to utilise opportunistic change when it arises. In a review of the theory and practice of knowledge brokering, the CHSRF (2003) outlines the skill set necessary or desirable for knowledge brokering. This includes

- the capacity to gather and critically appraise evidence

- the ability to see the 'big picture'

- good communication and mediation skills

- curiosity and listening skills.

These suggest that the knowledge broker requires a specific set of skills that is different from those needed by researchers in general, although clearly building on a set of common competencies. The real strength of knowledge brokering is the ability to understand both sides of the policy and research worlds, preferably in terms of content and process. Knowledge brokers also need skills in the art of persuasion. These skills alone, however, are not sufficient and could lead to inappropriate policy action - for example, when lobby groups for specific narrow interests are able to influence policy. The knowledge broker must therefore also have the skills to understand, categorise and synthesise evidence and research to ensure that the best research is informing policy, while at the same time understanding which policy levers are best suited to implement change. This is the cutting edge of knowledge brokering and suggests that the most successful knowledge brokers are those who have the capacity to bring together the art and science of influence to effect change.

\section{Environments that facilitate knowledge brokering}

The policymaking environmental context is an important one to consider for successful knowledge brokering. Policy environments can often change rapidly. Figure 6.1 outlines the aspects of the policy environment that enable change 
when they co-occur. For example, Kingdon (1995) argues that in order to open a policy window and influence the decision-making agenda, three separate yet linked ideas need to come together at a critical time. These are recognition of a problem (data), identification of a potential solution pathway within a policy framework (evidence-based strategies) and a political imperative where there is potential for commitment and the constraints are not too severe. These then support the broader constructs that Moore (2007) suggests are necessary for governments to perform well-namely: 1) capability (for example, personnel, skills, infrastructure); 2) a notion of public value in the change processes and results (important for political will); and 3) authority to progress change and respond accordingly (for example, through funding).

It is important to remember that outcomes for children and youth (health, development and wellbeing) also cross policy sectors and therefore the paradigms that must be brokered are not only research-to-policy within a sector, but between sectors. The knowledge broker must consider the best opportunities and methods to facilitate these change processes given the policy environmental context at the time.

Figure 6.1 The knowledge broker sphere of influence

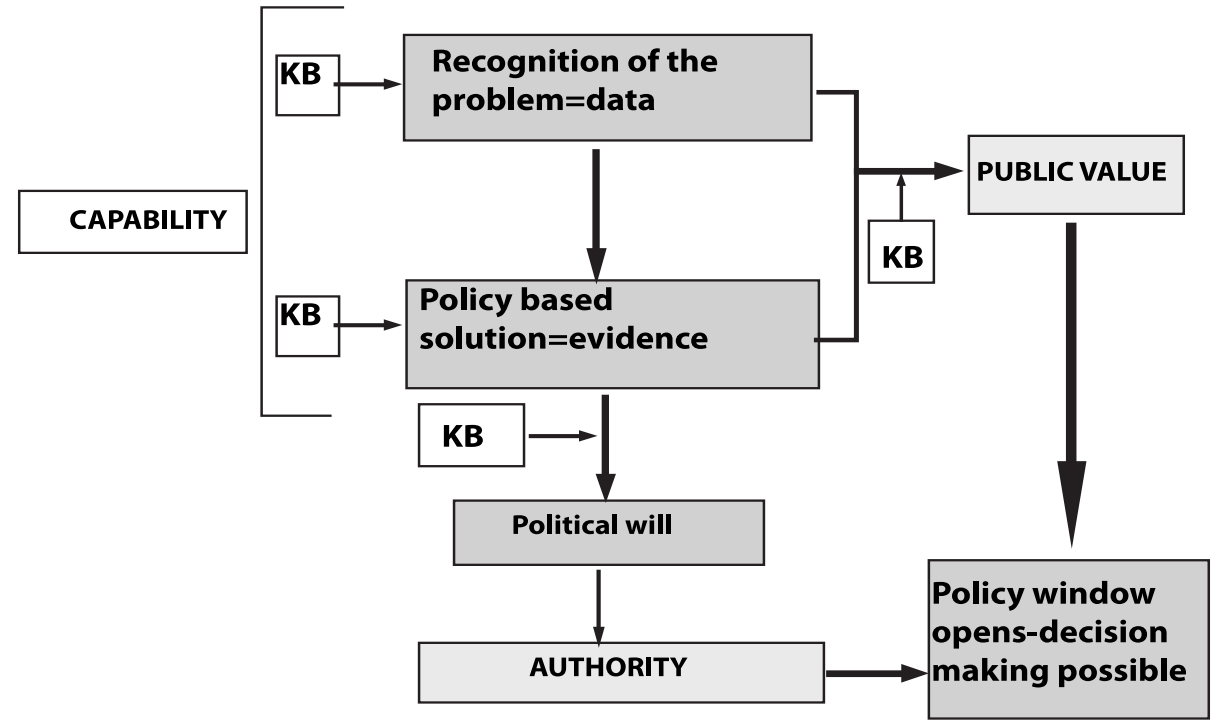

Adapted by Goldfeld from Kingdon (1995) and Moore (2007). 


\section{The art and science of knowledge brokering: examples of successful strategies}

The knowledge broker can act in a number of differing ways, depending on the opportunities that present themselves. Following are three examples demonstrating where the knowledge broker has played an essential role in helping to achieve an outcome. It is important to note that knowledge-brokering processes are not always heralded or obvious; rather they are often subtle and unnoticed. Knowledge brokers often place leadership in the hands of others, allowing the message to be taken up by those who have authority and the ability to make real change. Knowledge brokering also requires strategic thinking and opportunistic discussions, with an agenda planned well ahead of time.

In each of these examples, the principles outlined by Gladwell are considered in terms of: 1) who are the leaders that need to be engaged as champions and who else can echo this message to others; 2) what is the key message or story that needs to be told - the 'sticky message'; and 3) what are the environmental opportunities? Therefore, for each example, the methodology has varied to make the most of the environmental context. The processes have all been iterative and there has been variable success; however, they hopefully highlight the added value of a knowledge broker in transforming environments and enabling change.

While these examples focus mainly on embedding an evidence-based approach in the policy world, it is similarly important to work with researchers to help craft their ideas and projects within a policy context. It is by understanding the constraints that policymakers work within that opportunities that are often missed can be better realised by researchers and policymakers alike. For example, discussing with policymakers research ideas at an early stage of thinking will ensure that the researcher understands where their work might best be positioned (and whether the research is timely or should perhaps be rethought), and the policymaker already knows that the research they are interested in is under way. It is win-win.

Finally, while each of these examples discusses the specific role of the knowledge broker, it is important to note that none of the work described has been undertaken by the knowledge broker in isolation. For each example there was active recruitment of 'like-minded' colleagues and leaders to be both active change agents (the law of the few) and those who were the transmitters of the message. 


\section{Example 1: priority setting for children}

Understanding the problems facing children today requires us to start from a public health and prevention approach to child health, development, learning and wellbeing; to recognise the importance of social determinants and an ecological explanatory framework as central to guiding future action; and to consider outcomes that require a focus on early identification and management within this process. Four areas emerge from the literature (National Research Council Institute of Medicine 2000; Ochiltree and Moore 2001).

First, contemporary research now emphasises the importance of the first few years of life on the child's developing brain. Brain development in those early years is very dependent on the quality of the care environment. A secure start makes a difference.

Second, biological and environmental factors in the early years are seen to have consequences in later life - for good and sometimes for ill. Poor literacy skills, early school leaving, aggression, adult mental health problems, violent behaviour, criminality and medical conditions including obesity, diabetes and cardiovascular disease can all be seen to have precursors in early childhood.

Third, a body of evidence is suggesting how early intervention is cost effective. Interventions can significantly alter the developmental pathways of children and improve a range of adult outcomes. There are multiple benefits from such an investment.

Fourth, there is evidence of how improved outcomes can best be gained. Effective interventions recognise the intense commitment of parents, and other primary carers, and support this. They are based on parental and family involvement, community development and local identification of gaps and solutions.

In 2004, the Victorian Government undertook a priority-setting process to determine where it should focus effort in regard to children's outcomes. Reviewing this evidence base was essential if the Victorian Government, and particularly the Department of Human Services, ${ }^{1}$ was to know where it should focus its attention - that is, how to invest as wisely as possible when faced with competing choices. In developing policy, there are often competing agendas. The priority-setting approach offers the opportunity to ensure the development of evidence-based policy that focuses on the issues that need to be addressed and for which there are effective interventions (Department of Human Services 2004).

1 In 2009, the Department of Human Services split into the Department of Health and the Department of Human Services. 
From the knowledge-brokering point of view, this was a vehicle to: 1) raise awareness about the importance of outcomes for children across a range of stakeholders within government, including senior decision makers; 2) integrate an evidence-based approach into priority setting; 3) challenge decision makers to consider what effective interventions were not being implemented, and what ineffective interventions were continuing to be funded; and 4) engage policymakers in a process that focused on evidence and outcomes, rather than outputs and programs.

There were two key roles for the knowledge broker in the process. First, there was a need to work actively with policymakers, using evidence-based priority-setting tools to determine the overall priorities for children (creating the evidence-based messages). A priority-setting methodology was applied to children's outcomes and determinants, with scoring against prevalence, efficacy of intervention, impact and community concern. Two different equations were applied to the scores to produce two alternative lists of priority areas. Once the issues were ranked for each equation, a threshold line was established to delineate the priorities.

In this role, the knowledge broker was able to transfer the scientific evidence into a policy context. Once this was completed, however, there was a risk that the process would stall as a venture without authority (see Figure 6.1). Therefore, although there was a good understanding of the evidence by a number of policymakers, further commitment (the 'tipping point' in policy terms) was unlikely without senior management being able to transmit the message. The risk in this process was that knowledge would be brokered, but there would be no lasting effect. It was at this point that the art of knowledge brokering became most influential and helped facilitate the involvement of the highest levels of management from within government. For sustainability, the process required broader strategic thinking and influence (being the brokering of evidence) to ensure there were leaders to make the final decisions about priorities and convert the 'sticky' messages to action. Knowledge brokering in this context required the recruitment of others (the 'law of the few') to influence senior leaders as to the value of this process in determining priority efforts for children. The outcome was that cross-departmental groups were established to work on four key priorities for children with the imprimatur of the senior executive. In this case example, knowledge brokering assisted the policy and political processes by using data and evidence to recognise the issues for children and articulating policy-based solutions through priority setting. Although the science was necessary to consider evidence within a policy context, the art of knowledge brokering was necessary to ensure that priority action areas for children could continue to be addressed within usual departmental processes and would not be sidelined or ignored. 


\section{Example 2: establishing the Victorian Child and Adolescent Monitoring System}

It is clear from Figure 6.1 that data capability is an important aspect of successful and sustainable policy processes. It could be argued that without data there is little chance of successful change (or any way of knowing whether outcomes have been achieved). The role of data and information in shaping policy and setting government agendas has never been more critical. In an environment of competing agendas linked to both economic and political outcomes, data have the capacity to significantly alter where decision makers will finally focus attention and commitment as well as ensuring there is a capacity to evaluate the effectiveness of programs where significant funding has been applied. Data should therefore be considered the core of any agenda for children.

This idea has been reinforced nationally (Goldfeld and Oberklaid 2005) and internationally. For example, Rigby et al. (2003), in their paper on the European indicators of child health ('Child Health Indicators of Life Development', or 'CHILD'), noted that data 'should be in the centre of child health and not at the periphery of health monitoring'.

In this example, the knowledge-brokering function was to capitalise on the opportunity that presented itself through the establishment of the Office for Children in the Victorian Department of Human Services in 2005. The office was clearly committed to children's health, development, learning, safety and wellbeing. While the department already monitored a range of childrelated outcomes, only limited data were collected on a reasonably universal basis. Although some data were collected by other agencies, including other departments and the Australian Bureau of Statistics, neither departmental nor external sources covered all priority areas, particularly newly emerging issues of concern. Additional ways of collecting data were required. Establishing the Victorian Child and Adolescent Monitoring System (VCAMS) (Department of Education and Early Childhood Development 2007) within the Office for Children $^{2}$ was a critical step in ensuring that data would remain central to policy for children in the short and long term and be available for future knowledgebrokering processes. The objectives of VCAMS were to

- build a state-wide integrated monitoring and reporting system that was directly linked to policy and planning activities

- develop continuing data-collection strategies to address data gaps

2 The Office for Children merged with the Victorian Department of Education to become the Department of Education and Early Childhood Development in 2007. 
- ensure data were available, analysed and utilised for policy, planning, evaluation and research

- report regularly on the health, development, learning, safety and wellbeing of Victoria's children and adolescents.

In helping to establish VCAMS, the knowledge broker played a more traditional brokering role: preparing information for high-level decision makers that would enable them to make evidence-based decisions. Key to this process, however, was ensuring that policymakers at all levels of decision making understood the importance of data and would therefore support any further developments necessary over time and utilise the data for their own policymaking. In parallel with internal influence, external advice was also sought, capitalising on relationships with researchers to ensure that any proposals were based on the best science available. Clearly, having established networks across the research and policy arenas was of major benefit.

Using Gladwell's principles again, the power of context was very important for this process. Although there had been much advocacy for better data collection and monitoring of outcomes in the previous two years, it was only the establishment of the Office for Children - with a direct mandate to report on children's outcomes - that enabled the developmental and conceptual work for VCAMS to be undertaken. Subsequently, all of the objectives of VCAMS have been met to some extent (Cleary et al. 2008), including the development of an outcomes framework (Goldfeld et al. 2007) and two state-wide reports (Hood et al. 2006, 2008).

\section{Example 3: creating data for planning and community development}

The knowledge broker can also act to influence change at the local government or community level. This example focuses on research into policy and practice at the local level.

The Australian Early Development Index (AEDI) is a population measure of child development completed by teachers on children in their first year of formal schooling. The AEDI covers the domains of physical, social, emotional, cognitive and language development as well as general communication. The data are collected on all children in a geographic area, thereby providing small area-level data.

The Australian Early Development Index: Building Better Communities for Children project was undertaken in 54 communities throughout Australia, providing results, reports and maps describing how children in each area were 
developing by the time they reached school age (Centre for Community Child Health and the Telethon Institute of Child Health Research 2007). The project was conducted by the Centre for Community Child Health in partnership with the Telethon Institute for Child Health Research. It was an initiative of the Australian Government's National Agenda for Early Childhood with support from Shell Australia. In 2008, the incoming Rudd Government committed to a national roll-out of the AEDI with continuing funding from the Australian Government. While the story of how the AEDI came to be funded and then grew to the stage of a national roll-out is also a story about knowledge brokering (Goldfeld et al. 2008), the focus of the discussion below is on how knowledge brokering at a local level can have a substantial impact on the uptake and utility of the data at a local level.

Although knowledge brokers have traditionally been considered within the central government and policymaking contexts, the increasing program and policy activity aimed at children in local communities opens an opportunity for locally informed knowledge brokers to take a stronger role. The communitylevel knowledge brokering and the accompanying need to effect change are in some ways a microcosm of what can be seen at the broader policy level. The local ability to create a tipping point can, however, be far more probable.

For example, through the AEDI data-implementation process, communities must consider how they might change outcomes for children. This requires a knowledge broker to: 1) explain the nature of the data for that community (for example, by holding forums at which the results are properly explained); 2) facilitate the bringing together of stakeholders from various sectors within the community such as cross-sectoral strategy meetings to plan actions as a result of the AEDI; and 3) work with local governments to empower communities to effect change (for example, by advocating for certain evidence-based interventions or policy changes that are likely to result in local improvements). The knowledge broker therefore has to assess the evidence, interpret it for local circumstances and market or communicate the results. In this context, experts (or more centrally based knowledge brokers) can work with local leaders to build local knowledge-brokering capacity.

In once again taking up Gladwell's principles about the importance of messages, the environmental context and leadership, the knowledge broker can act to help communities better understand how to utilise the results of the AEDI (the message) to create change at a local level (context).

There is therefore impetus - at least in this context - to ensure that local knowledge brokers have the full range of skills necessary to galvanise the community, utilise the data evidence and consider how best to synthesise and communicate the research evidence that responds to the data and will most 
likely result in improved outcomes for local children. In the evaluation of the AEDI, it is clear that the AEDI process itself (as well as the results) has been successful in promoting the emerging concept of the local knowledge broker. In a number of areas, local leaders have emerged to bring stakeholders together to discuss early childhood and have utilised the AEDI to galvanise local action, bring in funds and consider the most effective community responses to the results (Sayers et al. 2007).

\section{Conclusion}

In Australia, there are significant areas of concern about children's health and development, with increasing disparities (especially for Indigenous children) and many health issues on the rise (Richardson and Prior 2005). At the same time, there is increasing interest from governments in improving the lives of children. In order to capitalise on the policy environment, however, and influence social change over time for all children, there is a pressing need to build capacity (through the policy and research fields) for knowledge brokering in child health and development. While it is important for researchers to actively engage with policymakers in the development and dissemination of research, knowledge brokering requires more active, sustained and planned effort than discussions or forums. Further, in actively developing more knowledge brokers, we should not underestimate the importance of the art of persuasion and communication in brokering the science of evidence.

\section{References}

Bronson, R. C., Rover, C., Ewing, R. and McBride, T. D. 2006, 'Researchers and policymakers: travellers in parallel universes', American Journal of Preventive Medicine, vol. 30, no. 2, pp. 164-72.

Canadian Health Services Research Foundation (CHSRF) 2003, The Theory and Practice of Knowledge Brokering in Canada's Health System, Canadian Health Services Research Foundation, Ottawa, viewed 3 May 2010, <http://www. chsrf.ca/brokering/pdf/Theory_and_Practice_e.pdf>

Canadian Health Services Research Foundation (CHSRF) 2008, Glossary of Knowledge Exchange Terms as Used by the Foundation, Canadian Health Services Research Foundation, Ottawa, viewed 3 May 2010, <http://www. chsrf.ca/keys/glossary_e.php> 
Centre for Community Child Health and the Telethon Institute of Child Health Research 2007, AEDI Community Results 2004-2006 Report, Centre for Community Child Health and the Telethon Institute of Child Health Research, Subiaco, WA, viewed 3 May 2010, <http://video.wch.org.au/aedi/ AustralianCommunitiesApril07.pdf>

Cleary, J., Goldfeld, S., Gabriel, S. and Siemon, D. 2008, 'Information for action: developing the Victorian Child and Adolescent Monitoring System (VCAMS)', Australasian Epidemiologist, vol. 15, no. 3 (December), pp. 19-23.

Department of Education and Early Childhood Development 2008, Victorian Child and Adolescent Monitoring System, Department of Education and Early Childhood Development, Government of Victoria, Melbourne, viewed 29 September 2008, <http://www.education.vic.gov.au/ocecd/statewideoutcomes.html>

Department of Human Services 2004, Establishing Priorities for Gain: The health, development, safety and wellbeing of Victoria's Children, Department of Human Services, Government of Victoria, Melbourne.

Gladwell, M. 2002, The Tipping Point: How little things can make a big difference, Little, Brown and Company, New York.

Goldfeld, S. and Oberklaid, F. 2005, 'Maintaining an agenda for children and young people: the key role of data in linking policy, politics and outcomes', Medical Journal of Australia, vol. 183, pp. 1-3.

Goldfeld, S., Muth, P. and Siemon, D. 2007, 'The Victorian child and adolescent outcomes framework', Child Outcomes, issue 1, Department of Education and Early Childhood Development, Government of Victoria, Melbourne.

Goldfeld, S., Sayers, M., Brinkman, S., Silburn, S. and Oberklaid, F. 2008, 'The process and policy challenges of adapting and implementing the Canadian early development instrument in Australia', Early Education and Development, vol. 20, no. 6, pp. 978-91.

Hood, S., Goldfeld, S., Muth, P., Cleary, J., Farooqui, A. and Hayes, L. 2006, The State of Victoria's Children Report 2006, Department of Human Services, Government of Victoria, Melbourne.

Hood, S., Lamb, K., Elkington, D., Grant, M. and Apted, H. 2008, The State of Victoria's Young People, Department of Education and Early Childhood Development and the Department of Planning and Community Development, Government of Victoria, Melbourne. 
Kingdon, J. 1995, Agendas, Alternatives and Public Policies, Second edn, Harper Collins College, New York.

Moore, M. 2007, Creating Public Value: Strategic management in government, Second edn, Harvard University, Cambridge, Mass.

National Research Council Institute of Medicine 2000, From Neurons to Neighbourhoods, National Academy Press, Washington, DC.

Ochiltree, G. and Moore, T. 2001, Best Start for Children. The evidence base underlying investment in the early years, Department of Human Services, Government of Victoria, Melbourne.

Richardson, S. and Prior, M. 2005, No Time to Lose: The well-being of Australia's children, Melbourne University Press, Vic.

Rigby, M., Kohler, L., Blair, M. and Metchler, R. 2003, 'Child health indicators for Europe: a priority for a caring society', European Journal of Public Health, vol. 13, no. 3, pp. 38-46.

Sayers, M., Coutts, M., Goldfeld, S., Oberklaid, F., Brinkman, S. A. and Silburn, S. R. 2007, 'Building better communities for children: community implementation and evaluation of the Australian Early Development Index', Early Education and Development, vol. 18, no. 3, pp. 519-34.

Snow, J. 1885, On the Mode of Communication of Cholera, John Churchill, London. 